\title{
A Dry Paint Recycling System with a Cube and a Circulation Filter
}

Filter boxes made from cardboard combined with circulation filters create flexible, highly efficient, clean and cost-effective paint recycling systems.

$T^{\mathrm{h}}$ he Edrizzi Vario dry filter range from Brainflash consists of three different paint recycling systems covering all the applications within the surface technology industry (see IST III-2014). However, the cubes simply form the basis for an intelligent painting concept.

\section{A service life of up to a year}

Circulation filter systems have been in use in paint shops for several years. The combination of filter boxes (Vario) and circulation filters results in a highly efficient dry paint recycling concept with a separation rate of up to $99 \%$ for fastdrying surface coatings. With this variant, the follow up filtration has a service life of up to a year.

The system consists of a housing made from galvanised steel sheet with

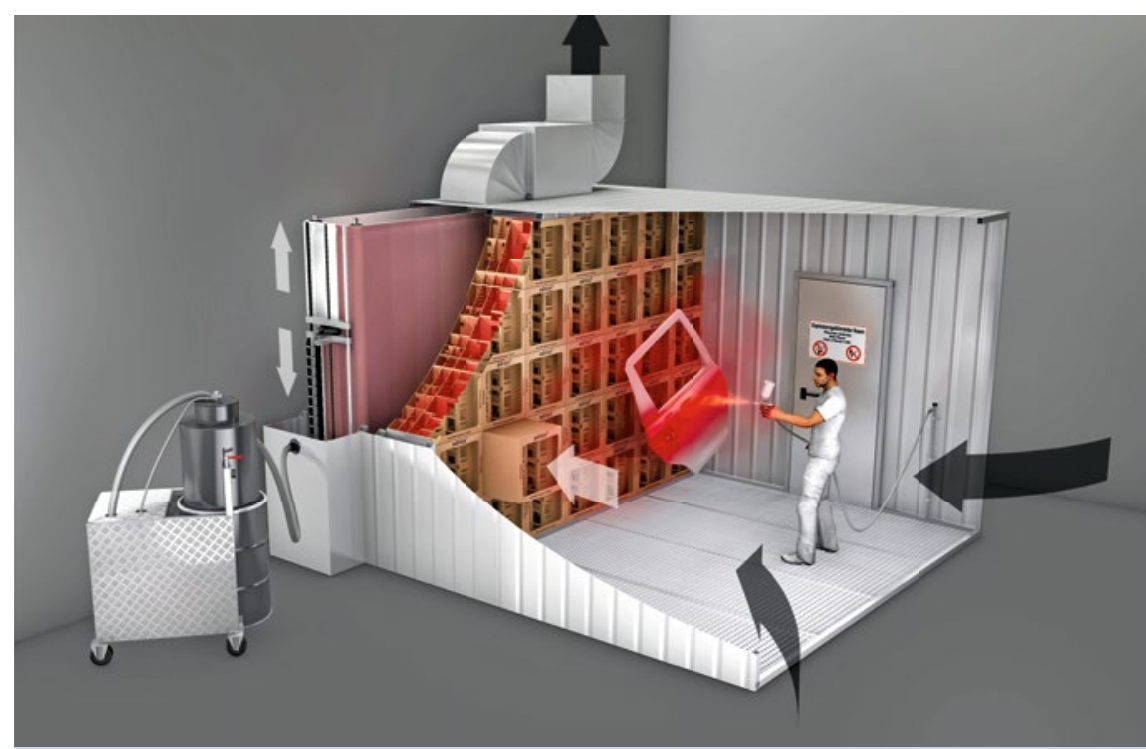

The majority of the overspray is removed by the filter cubes. The circulation filter fleece behind them functions as an after filter. The fine dust trapped by the fleece is continuously transported to the dust collector (left). a paint recycling system and an extraction box, a continuous circulation filter fleece, a drive system and an extraction unit.

The filter cubes contain the first level filters, which remove the majority of the overspray. The circulation filter fleece behind them functions as the after filter. The fleece traps the remaining fine dust and transports it continuously to the cleaning unit.

This is a self-cleaning dust collector where the dried paint dust is extracted from the circulation filter fleece using a clean and efficient process and collected in a 200-litre tank. This means that the circulation filter fleece remains constantly absorbent. The air extraction system is the same as that in conventional spray booths and consists of extractor fans. The fil-

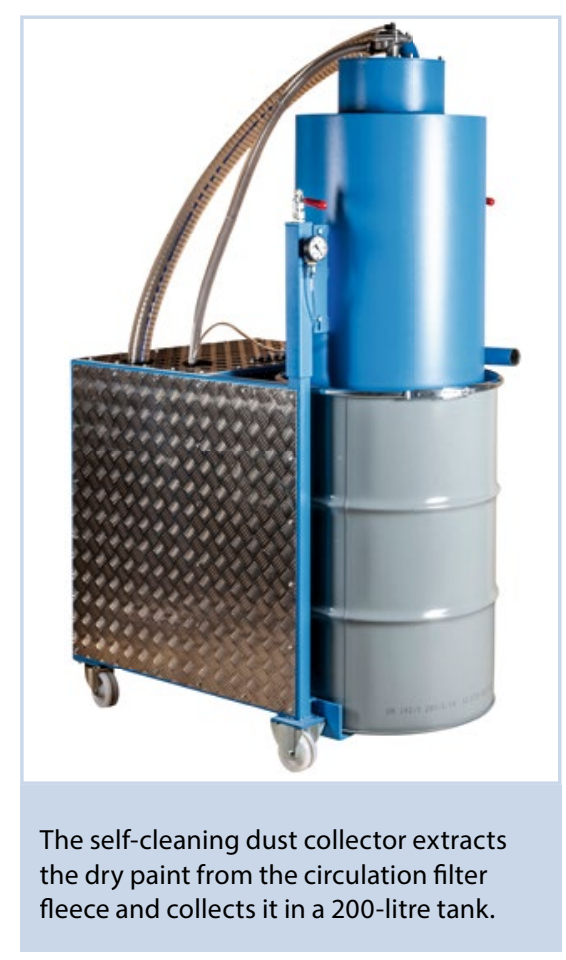

ter cubes and the circulation filters can be installed vertically or horizontally. They can also be retrofitted in existing paint shops easily and cost-effectively. The combination of filter cubes and circulation filters is a very clean solution for all types of paint shops, from simple manual spray booths and high-performance underfloor systems to automated paint lines. I

\section{Michael Eder}

Geschäftsführer, Brainflash Patententwicklungs GmbH, Lienz, Österreich,

Tel. +43485272674 ,

office@brainflash.at, www.edrizzi.com 